\title{
Blending asynchronous and synchronous digital technologies and instructional approaches to facilitate remote learning
}

\author{
Benjamin Luke Moorhouse ${ }^{1}$ (D) Kevin M. Wong ${ }^{2}$ (D)
}

Received: 22 January 2021 / Revised: 28 May 2021 / Accepted: 5 July 2021 /

Published online: 14 July 2021

(C) Beijing Normal University 2021

\begin{abstract}
This two-stage qualitative-dominant sequential mixed-method study, using an online survey of elementary and secondary school English language teachers $(N=73)$ and follow-up interviews $(N=10)$, collectively explores how teachers in Hong Kong adapted their instruction to online teaching in responses to COVID-19. The findings indicate that teachers used a variety of asynchronous and synchronous digital technologies and instructional approaches to facilitate students' learning, assess learning, and communicate with students and parents remotely. The findings suggest that a blend of asynchronous and synchronous modes are seen as optimum to support student learning online. A model is proposed on how teachers can blend asynchronous and synchronous digital technologies and instructional approaches within a sequence of learning.
\end{abstract}

Keywords Blended learning · COVID-19 - Digtial technologies · Online learning · Virtual schools $\cdot$ Distance learning

Benjamin Luke Moorhouse

blmoorhouse@hkbu.edu.hk

1 Department of Education Studies, Hong Kong Baptist University, AAB836, Academic \& Administration Building, Baptist University Road Campus, Kowloon Tong, Hong Kong

2 Graduate School of Education and Psychology, Pepperdine University, Los Angeles, CA, USA 


\section{Introduction}

The integration of technology and digital modes of learning into schools and classrooms has been gradually expanding in recent years (Bond, 2020; Schuetz et al., 2018; Taghizadeh \& Yourdshahi, 2019). It can be common, in many contexts, for learners to use tablets in class (Bjørgen et al., 2021) and be required to complete homework assignments online (Magalhães et al., 2020). To help teachers conceptualise how they can integrate digital content and tools into their in-person classroom, the International Association for K-12 Online Learning (iNACOL, 2011) proposes a model for blended learning (see Fig. 1). This model is useful in helping teachers consider ways of utilising resources, assessing learning and communicating with stakeholders with various degrees of digital integration. However, the model reserves synchronous learning for the physical classroom and asynchronous learning for online-seeing blended learning as a blend of the physical/online. Furthermore, the model does not provide suggestions on how teachers may sequence learning using different modes.

While in most countries, primary and secondary education still occurs in the in-person classroom, there has been growing popularity of virtual schools and distance learning in primary and secondary school years around the world (Barbour \& Reeves, 2009). This increase is, in part, due to the benefits virtual schooling reportedly brings, including expanding educational access, providing high-quality learning opportunities, improving student outcomes and skills, and allowing for educational choice (Berge \& Clarke, 2005). However, despite their increase in popularity and their potential benefits, there is still a lack of best-practices data, and there is limited amount of research related to teaching and learning in virtual schools (Dipietro, 2010; Toppin \& Toppin, 2015). Therefore, learner success within virtual schools is largely dependent on the teacher's ability to plan, implement and assess their online teaching and courses (Rozitis, 2017; Toppin \& Toppin, 2015). This state of affairs has led scholars to suggest that good virtual schooling should be driven by sound instructional approaches (Moller et al., 2012). Yet, developing and designing online courses is more complex and different from an in-person course (Wang, 2021) with teachers needing to consider content, activities (including synchronous and asynchronous activities), facilitation and evaluation (Wang, 2021) all within the constraints of the physical and possible relational distance between the student and teacher. Indeed, "established techniques for student success in traditional classrooms do not always work in distance courses" (Serwatka, 2002, p. 48). Teachers and virtual learning course designers, therefore, require instructional models which can guide their pedagogical decision-making.

This study aims to address the current gaps in our understanding regarding online primary and secondary education by contributing to the best-practice data and proposing a model of how teachers can blend asynchronous and synchronous digital technologies and instructional approaches within a sequence of learning. Addressing these gaps is even more pressing, at the current time, as many physical schools have become 'temporary virtual schools' due to COVID-19 (Hodges et al., 2020). Many teachers have reported feeling ill-prepared for online-only instructional practices 
(Moorhouse \& Kohnke, 2021; Morgan, 2020; Wang, 2021) while teachers can often lack professional development in this key area (Chai \& King, 2017; Sánchez-Cruzadoetal. 2021). Though the disruptions to education of COVID-19 are likely to subside, the affordances of online teaching mean virtual schools will continue to be a feature of primary and secondary education (Barbour \& Reeves, 2009). The current study's aims are achieved through an investigation of how Hong Kong English language teachers designed, implemented, and leveraged synchronous and/or asynchronous technologies and instructional approaches to teach learners during the COVID19 pandemic.

\section{Digital technologies and instructional approaches}

From the late twentieth century to the beginning of the twenty-first century, the development of digital technologies has made a significant impact on the way we work, play, and connect with one another. Initially, the effects of digital technologies on education were relatively minor as generic technologies had limited usefulness in the classroom or the work of teachers (Cuban, 2001). However, in recent years, digital technologies specifically designed for education or with greater utility in the classroom, such as presentation software, learning management systems (LMS), student response systems (SRS), and game-based learning platforms (GBLP), have begun to play prominent role in education (Moorhouse \& Beaumont, 2020a; Tay et al., 2017; Voogt et al., 2018), while teachers' administrative responsibilities are also becoming increasingly digitised (Shah, 2014). These changes have coincided with the development of internet-ready, handheld devices, such as tablets, and Wi-Fi connectivity, meaning teachers no longer need to take students to computer labs or to use expensive laptops; rather, they can utilise the handheld devices in the classroom (Hockly \& Dudeney, 2018).

In Hong Kong, the Education Bureau has promoted the use of digital technologies in schools and has made grants and funds available to provide access to these technologies (Kong et al., 2017). Schools have purchased suites of tablets, installed $\mathrm{Wi}-\mathrm{Fi}$ and initiated bring-your-own-device schemes. Along with these advancements has been the development of instructional approaches and models, such as the flipped classroom and blended learning (Carrier \& Nye, 2017; Hockly \& Dudeney, 2018; Pulham \& Graham, 2018). The flipped classroom approach involves students engaging with content outside of lesson time, usually via videos, before an in-person class (Bond, 2020).

To date, there has been a dearth of research on the use of these models in primary and secondary school contexts. Most research that has been done has focussed on the integration or blending of digital technology into the in-person classroom. For example, Tay et al. (2017) explored the integration of digital technology into a primary school in Singapore. They found that successful integration was dependent on the instructional approaches adopted by teachers. Bond (2020) conducted a systematic review of 107 publications and documents pertaining to the use of flipped classrooms in primary and secondary schools. The author found a positive association between flipped classrooms, student engagement and learning, with teacher-made 
videos and the use of collaborative digital technologies (e.g. a LMS). However, she also reported a need for further research to include the perceptions of teachers. In addition, Pulham and Graham (2018) conducted a literature review of teaching documents to identify the competencies primary and secondary teachers need to conduct blended learning, along with technological knowledge, such as using an LMS, and the ability to be flexible and personalise teaching content. Moreover, Pulman and Graham found that teachers need knowledge of instructional approaches and design. Like Bond (2020), Pulman and Graham highlighted the lack of published research regarding blended learning in primary and secondary schools.

In response to COVID-19, scholars have begun to explore teachers' shifts and adaptations to online instruction (e.g. Cheung, 2021; Moorhouse \& Beaumont, 2020b). For example, Moorhouse and Beaumont (2020b) explored one teacher's use of a video-conferencing system (VCS) to deliver synchronous online lessons to primary school learners in Hong Kong. They provided several suggestions for teachers new to synchronous online teaching, including providing time for students to become familiar with the technology, utilising various features of the VCS (e.g. 'share screen' and 'gallery view'), and including the synchronous lesson within a sequence of learning. They suggested that the sequence should include a pre-task, so students come prepared, and a post-task to extend the learning beyond the lesson.

In post-secondary or tertiary education where online (or distance) teaching and learning has been a popular and growing mode of education for over two decades (Allen \& Seaman, 2016; Horvitz et al., 2003; White, 2003), more research has been conducted. In post-secondary education, there is a variety of instructional approaches adopted. Horvitz et al., (2019) identified four categories of instructional approaches in community colleges in the United States, these included: (a) a hybrid or blended course with asynchronous online lecturers; (b) a hybrid or blended course with synchronous lectures; (c) a hybrid or blended course with a combination of asynchronous and synchronous lectures and discussions; and (d) a course that is fully online (pp. 241-242). While their study provides a useful overview of instructional approaches for online teaching, it does not examine the benefits of each approach, nor potential ways of sequencing learning by combining various technologies and instructional approaches.

The literature review has shown that while digital technology is taking an increasingly important role in primary and secondary school learning, most research has explored its utility and related instructional approaches within in-person teaching contexts (e.g. Tay et al., 2017), but not in fully online contexts. Although comparatively more research has been conducted in post-secondary education, there are still limitations on what we know about how various digital technologies and instructional approaches can be blended into a sequence of learning. This study will begin to fill this gap.

\section{Conceptual framework}

As mentioned above, the International Association for K-12 Online Learning (iNACOL, 2011) provide a model showing the degrees of online instruction and the 
impact this has on teaching practices, such as instructional resources (or digital technologies), assessment, and communication (see Fig. 1). This model is useful for understanding how online instruction can be used to expand and enhance the

\begin{tabular}{|c|c|c|c|}
\hline & Less online instruction & $\begin{array}{l}\text { More online } \\
\text { instruction }\end{array}$ & $\begin{array}{l}\text { Mostly online } \\
\text { instruction }\end{array}$ \\
\hline & \multicolumn{3}{|c|}{ Online Instruction } \\
\hline \multicolumn{4}{|c|}{ Less -----------------------More----------------------Mostly } \\
\hline Instructional & Course minimally uses & Digital content, & Use of digital resources \\
\hline \multirow[t]{4}{*}{ Resources } & digital content, & resources, and tools & and tools are integral to \\
\hline & resources, and tools to & expand and enhance & content, curriculum and \\
\hline & supplement instruction & the curriculum and & instruction \\
\hline & & content & \\
\hline \multirow[t]{7}{*}{ Assessment } & Whole-class & A combination of & Greater amount of \\
\hline & assessments, used & traditional and online & digital, real-time data \\
\hline & primarily in the & assessments are used & and feedback allow for \\
\hline & classroom, during the & inside and outside the & individualised \\
\hline & school day as the & classroom & instruction \\
\hline & primary means of & & \\
\hline & feedback & & \\
\hline Communication & Occurs primarily & Is a mixture of & Occurs primarily \\
\hline (Student / & synchronously and in & synchronous \& & asynchronously and \\
\hline teacher / Student & the physical classroom & asynchronous and & online or from a distance \\
\hline \multirow[t]{3}{*}{ \& Student) } & & may be in the & \\
\hline & & physical or classroom & \\
\hline & & or online & \\
\hline
\end{tabular}

Fig. 1 Dimensions of blended learning model—characteristics of instructional models (adapted from iNACOL 2011) 
curriculum and content or to become an integral part of the content, curriculum, and instruction.

Models such as Fig. 1 focus primarily on the blending of in-person classroom and asynchronous online instructional approaches. However, with recent advancements of technology, the use of VCS to teach primary and secondary school learners synchronously online has become a possibility (Peachey, 2017; Rehn et al., 2016, 2018). Synchronous online teaching involves teachers using VCS to teach live real-time lessons to their learners. This, therefore, provides the possibility of extending the definition of blended learning to include blending of asynchronous and synchronous online modes. Teaching synchronously online clearly brings additional challenges to teachers. Teachers need to effectively teach and communicate across a screen, manage multiple digital technologies simultaneously, maintain a sense of presence, facilitate real-time interaction, and troubleshoot technical interruptions (Rehn et al., 2018). Despite these challenges, synchronous online teaching allows teachers and learners to engage with one another in real time. They provide space for teacher-student and student-student interaction, engaging learners in group activities, responding instantly to student concerns and issues, and ensuring students feel supported to do any asynchronous work they are assigned (González-Lloret, 2020; Peachey, 2017). These advances provide online teachers with a greater choice of instructional approaches. However, online teachers require awareness of technological tools and online instructional approaches if they are to teach online effectively (Cleveland-Innes \& Garrison, 2012; Cong, 2020; Pulham \& Graham, 2018).

COVID-19 has had a devastating impact on humanity. However, it has also led to one of the biggest opportunities for innovation in education in human history. In nearly every country and territory, teachers have needed to find ways to support their students' learning outside of the physical classroom (Bozhurt \& Sharma, 2020). This has led to the wide-spread adoption of online teaching and learning in primary and secondary schools world-wide, effectively establishing thousands of virtual schools (Dhawan, 2020; Wang, 2021). This provides a unique opportunity to explore the digital technologies and instructional approaches teachers have employed at this time, which can add to our growing understanding of blended learning in relation to virtual schooling.

Using three essential aspects of the dimensions of blended learning model (adapted from iNACOL, 2011): instructional resources, assessment, and communication, as a conceptual framework, this current study investigates how Hong Kong English language teachers designed, implemented, and leveraged synchronous and/or asynchronous online instructional approaches to teach learners during the COVID-19 pandemic. It addresses the following research question:

- What digital technologies and instructional approaches have teachers in Hong Kong adopted during the suspension of in-person classes?

By using the case of Hong Kong primary and secondary school English language teachers, this study seeks to add to the growing body of literature around teachers' responses to COVID-19. By detailing teachers' practices, the study also seeks to provide suggestions for ways teachers can implement online teaching and virtual schooling beyond the pandemic. 


\section{Methods}

\section{Research model}

The current study used a two-stage qualitative-dominant sequential mixed-method design to investigate how Hong Kong English language teachers designed, implemented, and leveraged synchronous and/or asynchronous digital technologies and instructional approaches to teach learners during the COVID-19 pandemic. As the field of study has developed rapidly along with the spread of COVID-19, the twostage qualitative-dominant sequential mixed-method design, which included an online survey with quantitative and qualitative items followed by semi-structured interviews, allowed for a more holistic understanding and description of teachers' practices than a single method (Morse, 2010). Furthermore, it allowed for 'rich and complex accounts of the type of sense-making' of participants (Braun et al., 2020, p. 1) and, therefore, helped explore participants' lived experiences. The second stage allowed the researchers to further explore themes generated in the first stage, which is not possible in single-method studies (Hesse-Biber, 2010). This makes this research model preferred for the exploratory nature of this study.

\section{Data collection tools and process}

The first stage involved an online survey with quantitative and qualitative items to provide a general landscape of teachers' practices. The survey was purposefully developed for the study and underwent two rounds of piloting. In the first round of survey development, two teacher educators familiar with the context were asked to review the survey and provide comments on clarity and comprehensiveness (Nunan \& Bailey, 2009). In the second round, four teachers were asked to complete the survey. The researchers analysed their responses and compared them to the intended purpose of each item. Overall, the survey was able to achieve its purpose; however, some items were revised for clarity and purpose. This process helped ensure content and face validity and reliability of the data generated (Holden, 2010; Nunan \& Bailey, 2009). The finalised survey included three sections relevant to this study: biographical information; use of technology; and perceptions of technology (See Online Appendix 1 for the survey questions). The quantitative items were primarily designed to collect biographical and general information, while the qualitative items were designed to collect participants' specific pedagogical practices and perceptions of online teaching during the period of school closures. This makes more open-ended items particularly useful for this study due to its exploratory nature (Hesse-Biber, 2010). The survey was administered to 73 teachers at the end of March 2020. Due to the time sensitive nature of the study and the restrictions placed to limit human-to-human contact, participants were recruited through convenience sampling. The researchers sent the survey link through e-mail and instant messaging platforms to relevant contacts known to them with an invitation to complete the 


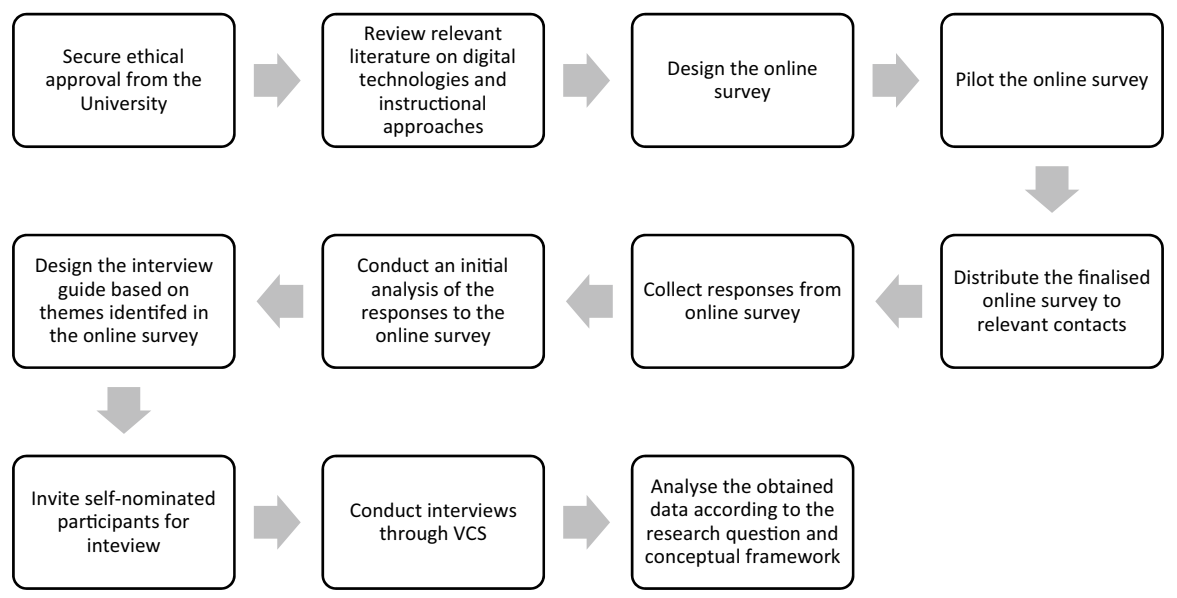

Fig. 2 Data collection process

anonymous survey. The link was active for two weeks. After participants completed the survey, they were given the option to self-nominate for follow-up interviews.

The survey dataset consisted of 49 primary school teachers $(67.1 \%)$ and 24 secondary school teachers $(32.9 \%), 45.2 \%$ had less than 5 years teaching experience, while $54.8 \%$ had more than five years. The sample represents the three main regions of Hong Kong (i.e. Hong Kong Island 37\%, Kowloon 30.1\%, New Territories $32.9 \%)$.

The second stage of data collection involved follow-up, semi-structured interviews with ten teachers who had completed the survey and expressed interest in participating. The interview guide was constructed in response to trends and themes identified during analysis of the survey data (See Online Appendix 2 for the interview questions). This allowed for a deeper exploration (Cohen et al., 2011) of the teachers' practices and the factors that influenced these practices. Ten teachers were selected based on their responses in the survey to represent primary and secondary school contexts, all three regions of Hong Kong, and asynchronously-only and blended instructional approaches. The interviews were conducted in April 2020 through VCS to minimise human-to-human contact and lasted between 55 and $70 \mathrm{~min}$. They were audio-recorded and transcribed. The steps taken in the data collection process are presented in Fig. 2. Ethical approval for the study was provided at the University level with all participants informed of the purpose and procedures of the study.

\section{Data analysis}

Quantitative data were analysed following standard statistical procedures to generate descriptive statistics appropriate to the data type, including percentages and frequencies (Cohen et al., 2011). Qualitative data from the survey and interviews were analysed using thematic analysis, with themes identified using the six-stage coding process proposed by Braun and Clarke (2006): 
1. The transcriptions were read and re-read to familiarise the researchers with the data.

2. Initial codes were generated by each researcher, and then compared systematically using a shared cloud stored online document with themes identified.

3. Within the themes, subthemes were identified.

4. The themes were reviewed by the two researchers and categorised using the conceptual framework of the three characteristics of blended learning: Instructional resources; assessment; and communication (iNACOL, 2011). For example, the themes 'Asynchronous resources to manage learning' and 'Synchronous resources to facilitate teaching' were categorised under 'Instructional resources.'

5. Themes from the survey and interviews were compared and compiled, with the researchers agreeing to the final themes.

6. Extracts were selected that illustrated the themes and the report was compiled.

To increase the reliability of the data analysis, throughout the processes, the researchers kept in constant communication: checking understandings, asking for clarification, and discussing differences in interpretations (Cohen et al., 2011).

\section{Findings}

Data analysis indicates that teachers adopted either a blend of synchronous and asynchronous instructional approach $(n=42,57 \%)$ or an asynchronous-only instructional approach $(n=31,43 \%)$ during the class suspension caused by COVID-19. The decisions to use asynchronous and/or synchronous technologies and instructional resources or a blend of both, were largely dependent on the affordances of each mode in helping the teacher address the needs of learners during the in-person class suspensions. To help understand these affordances, the relevant findings pertaining to each characteristic of the blended learning model (adapted from iNACOL, 2011), instructional resources, assessment, and communication are presented.

\section{Instructional resources}

\section{Asynchronous instructional resources to manage learning}

The survey results indicate that the use of LMS were wide-spread. All survey respondents indicated they used one platform, such as Google Classroom (49\%), eClass (or other school-based platforms) (26\%), and Seesaw (14\%). The platforms serve as a central point for teachers and students to engage in teaching and learning. Teachers choose LMS platforms, primarily based on their user-friendliness, the provision of engagement analytics, and their use by teachers and students before the suspension of in-person schooling. Therefore, they were familiar with its functions and purpose. One survey respondent wrote about the use of an LMS: 
[An LMS] is a good platform for issuing assignments and quizzes. Marking can be automatically done [on the LMS]. Results can also be analysed. I can evaluate students' performance simultaneously. The interaction is also active in [the LMS]. Students can ask questions about technology or assignment issues in [the LMS]. If I can't give responses instantly, peers will answer those questions.

Primary school teachers preferred LMS platforms that are specifically designed for younger learners. These included features such as built-in 'translation' and multimodal activity types like 'drawing' and 'video presentations.' The value of a LMS in online learning seemed almost self-evident to the participants. Students and teachers clearly need a familiar digital space to interact asynchronously, and conduct various activities associated with learning, such as uploading worksheets and materials, submitting assignments, and providing feedback.

\section{Asynchronous instructional resources to provide input for online learning}

To develop input for student learning, teachers created tailor-made videos that introduced content to students. To create the videos, a number of content-creation tools or presentation programmes were utilised, including Microsoft PowerPoint $(n=$ 13), Screencastify $(n=5)$, OBS studio $(n=2)$, iMovie $(n=2)$ and Explain Everything $(n=2)$. Presentation programmes were used to create teaching videos with voice over narration. These videos served as input to learning, where teachers could record their lesson for students to watch "whenever and wherever they are, regardless of the speed of the connection." This added flexibility to both students and teachers. The teachers were intentional about making videos engaging and short. One primary school teacher mentioned, "[Videos need to be] quite eye-catching and quite interesting so that [they] can catch students' attention because I can imagine them sitting in front of the computer all day." It also allowed them to personalise the content for their class and maintain a presence in their students' lives. Video Hosting Sites, such as EdPuzzle $(n=9)$, and YouTube $(n=12)$ were utilised to host the videos as they allowed teachers to track student views and engagement. A teacher described the process of creating a tailor-made video and uploading it using a presentation programme and video hosting site:

I have found that using the screen record function on later versions of [a presentation programme] has been very effective. In doing this, students can see your face in a small window in the bottom right of the slides (although the position can be moved). I think this makes the teaching more personal than recording voice only and hopefully better keeps students' attention... After the [presentation] is finished, I will export it as a video, which includes the screen record and annotations, and then upload the video to [a Video Hosting Site].

While the use of videos were seen as a good way to provide learning input, teachers believe they need to be combined with a follow-up activity. The videos were either followed-up with a synchronous lesson or a post-viewing assignment on an LMS. 


\section{Asynchronous instructional resources to create activities for online learning}

To create post-viewing exercises or modify activities and worksheets for online learning, a number of tools were leveraged, including Kahoot $(n=6)$, Quizlet $(n=4)$, Nearpod $(n=4)$ and Google Forms $(n=12)$. Survey administration software (SAS), such as Google Forms, were seen as good platforms to design and assign exercises as they can generate analytics on student participation and accuracy. A primary school teacher wrote, "The best way to assess student learning, I find, is [a $S A S]$. The [spread]sheet that [it] creates makes it very easy for me to evaluate the performance of the students." It also allowed for 'self-marking quizzes' that teachers found useful. Teachers mentioned the need to make the exercises and activities visually appealing so students felt interested in doing them independently. Even for short post-viewing personal response questions, in response to a song or other material, teachers found it useful to set a short quiz-something easily done orally in the inperson classroom, but more difficult online. They could embed the video in the form and ask a short personal response question. A primary teacher explains:

I created a [quiz on a SAS] [as a post-viewing activity to a song] and ask [students] if they enjoy listening to the song. [Normally], I can ask this question in the lesson freely, but now I can't. I don't know how to get their response. So, I try to put this kind of personal question inside [the SAS] and then I ask the students if they like the song. I want to know their personal experience.

The teachers recognised the need to sequence asynchronous activities so as to maximise the learning potential they afforded. For example, listening to a song or watching a video without a follow-up task, could reduce students' engagement in it, and also reduce the teachers' abilities to monitor student engagement and performance. Through completing a form on a SAS, students had incentives to complete the activities, while teachers gained valuable analytics on their performance.

\section{Synchronous instructional resources to facilitate teaching}

For the teachers who conducted synchronous online lessons and/or tutorials, they used different VCS platforms, including Zoom (86\%), Google Meets (9\%), Microsoft Teams (2\%) and Webex (2\%). Teachers used a variety of VCS platform features to facilitate their teaching. These included the scheduling functions to timetable lessons in coordination with colleagues; the 'Chatbox', 'raise-hand' icon, and 'voice' functions to provide multiple modes of interacting; The 'Share screen' and 'whiteboard' functions to combine the VCS other tools, such as SRS and production tools; the recording function to upload lesson recordings for self-study or for safety reasons, and the 'Breakout Rooms' function, which allows teachers to assign students to smaller groups for discussion. Breakout rooms were seen as a particularly useful feature, as they meant larger classes could be broken into small groups and students had more opportunities for discussion. As this teacher mentions, "So I do use the breakout rooms with my freshman in particular because it's harder to have a whole-class discussion with about 22 students." Teachers felt that there needed to be 
a product for any small group discussion, such as the construction of a presentation slide or the completion of an activity on SAS.

The utilisation of VCS platforms to teaching synchronously was seen as an important step in the teaching sequence. While asynchronous approaches could be used to provide learning activities for students to do in their own time, by bringing students together, and sharing time synchronously, teachers were able to simulate in-person lessons.

\section{Assessment}

\section{Asynchronous assessment and feedback}

Once students completed asynchronous activities or worksheets, teachers would then assess the work and provide feedback. In the in-person classroom, this would often entail individual written feedback on students' work and/or feedback to the whole-class in lessons. Teachers, therefore, need to conceptualise marking and feedback for online-only instruction. For closed questions on platforms such as Google Forms, Nearpod, EdPuzzle and Kahoot, the teachers utilised the selfmarking function that provided direct feedback to students. They also analysed the analytics generated by the platforms to inform them about students' participation (i.e. how long they spent on each question), effort (i.e. how many attempts they made), and accuracy (i.e. whether the answer is correct). This led to adjustments or additional instruction either asynchronously or synchronously. For example, one teacher noticed from the analytics created by Nearpod that some students would randomly guess the answers to questions and take 40-50 attempts at one activity. She was able to address this by creating an instructional video "going through the Nearpod slides, one by one, and then showing [students]: 'See, this is how you have to play and you have to get fewer number of [attempts]."'.

Open questions and activities were more challenging to assess and provide individual feedback. As some teachers wanted students to handwrite work and to limit screen time, these teachers would ask students to upload the work to the LMS, then print it off and hand wrote feedback on the hardcopy before scanning it and returning it to students. Others utilised annotation tools, such as DocHub or Perusal to provide individual online feedback. A secondary school teacher described the utility of Perusal:

You can program Perusal to look for [specific responses], and [students will] get a point if they've done it so it can do your marking a bit for you or help you out a little bit. You can kind of give [students] a heads up and be like, 'You know, there's three key lines in this text that are essential to understanding it. See if you can find them,' and you know they'll highlight away.

To provide feedback to the whole-class on common errors or highlight good work, teachers created feedback videos or conducted a synchronous lesson. These were seen as a way to personalise the feedback. Using tailor-made learning platforms and adapting tools designed for other functions, such as annotation tools, allowed 
teachers to simulate their in-person marking practices and ensure the important step of assessing and providing feedback was not absent from their teaching sequence.

\section{Synchronous assessment and feedback}

In addition to asynchronous assessment and feedback, synchronous approaches were also utilised. In fact, monitoring learning created an incentive for teachers to use synchronous approaches, as this teacher wrote, "[I use] 'Zoom Lessons' to follow-up learning. Students watch the videos by themselves and I found it much better to have a chance to meet the students and see how well they have learnt." Teachers could ask questions and provide instant feedback. The option to interact orally and in written form, as well as utilising the shared screen, meant the teachers had multiple ways to gather data on student performance and provide feedback to the whole-class, groups (in breakout rooms), or individually (through one-on-one consultations). To help maximise the live lessons and ensure they were effective, teachers believed it was important to use a variety of short, interactive activities and give clear instructions and rules to keep students busy and focussed. Rules such as muting mics and raising hands to answer questions are seen as important.

\section{Communication}

\section{Asynchronous communication and interaction}

As students were studying from home, teachers found different ways to maintain contact with them. Teachers leveraged the LMS to send regular announcements, which they believe served as an important strategy to keep students engaged. In addition, some teachers utilised e-mail, instant messaging platforms (e.g. Whatsapp and WeChat) or social media platforms (e.g. Instagram). These were seen as important mediums for students who did not complete work or join scheduled synchronous online lessons. Some teachers did note that if students disengaged completely, there were limited options available to them. Having multiple channels available for communication seemed essential for keeping students and teachers connected. While the LMS was a good platform for notices and announcements, students need to actively sign in to see the announcements. Therefore, instant messaging platforms provided a way to connect directly and instantly.

\section{Synchronous communication and interaction}

Synchronous lessons were seen as beneficial as they provided a way to interact with and between learners and maintain relationships with students during the suspension. Teachers utilised the various tools integrated into VCS platforms to promote interaction through multiple modalities. Teachers used the 'chat box' function for 
students to write questions and responses; the 'raise-hand' function so students can self-nominate to engage orally; and the 'shared screen' function to combine the VCS with other tools, such as production tools (e.g. Google slides), game-based quiz platforms (e.g. Kahoot!) or SRS (e.g. Mentimeter). Teachers largely use these methods to "avoid lecturing" and prevent students from going off-task or "becoming bored." Although teachers felt interaction during synchronous online lessons was different from in-person lessons and harder to facilitate, the affordances of the multiple tools built in to the VCS meant that they could engage students in real time.

\section{Discussion}

COVID-19 has required teachers to find alternative ways to continue teaching their learners. While many teachers were new to online-only modes of learning (Wang, 2021) and the approaches and strategies needed to teach online are different from in-person instruction (Serwatka, 2002), they have shown an ability to innovate for the benefit of their learners. This has led teachers to adopt asynchronous and/or synchronous digital technologies and instructional approaches to create emergency virtual schools.

The above findings were presented according to the three characteristics of the blended learning model (adapted from iNACOL, 2011), instructional resources, assessment, and communication. They show how teachers have utilised synchronous and asynchronous approaches based on the affordances of each mode. Asynchronous instructional resources provide a way for teachers to manage and create learning materials for students. Students can then engage the materials flexibly or when parental support is available. However, asynchronous technologies may provide limited opportunity for real-time interaction and regular communication between students and teachers. Therefore, teachers scheduled synchronous online lessons through VCS to provide real-time interaction. During these live sessions, the teachers used the various multimodal features of the VCS to facilitate their teaching (Peachey, 2017; Rehn, 2016, 2018). Similarly, teachers employed asynchronous and synchronous technologies to support them in assessing, providing feedback to learning, and creating modes of real-time and asynchronous communication.

It seems that neither asynchronous nor synchronous-only modes of teaching are enough alone to effectively instruct, assess and communicate with primary and secondary school learners, and instead a virtual blended approach is likely to provide the teachers with the tools needed. Therefore, the authors assert a new model, the 'Blended Online Instructional Sequence', that integrates asynchronous and synchronous online practices as a possible way for teachers to instruct, assess and communicate with learners in a sequence of learning remotely (See Fig. 3). The model, while informed by the findings from the study and related literature (e.g. Cong, 2020; Bond, 2020; Moorhouse \& Beaumont, 2020a; Moorhouse et al., 2021; Peachey, 2017; Wang, 2021), suggests a five-stage blended lesson sequence. In the first stage, a pre-live lesson task or activity is assigned, which could include watching a video and/or answering questions on a LMS or SRS 


\begin{tabular}{|c|c|c|c|c|}
\hline Mode & Instructional Approach & Pedagogical Rationale & $\begin{array}{l}\text { Digital } \\
\text { Technologies } \\
\text { Leveraged }\end{array}$ & Communication \\
\hline Asynchronous & $\begin{array}{l}\text { 1. Pre-live lesson task } \\
\text { a. Watch video } \\
\text { b. Answer questions }\end{array}$ & $\begin{array}{l}\text { Help learners prepare for the } \\
\text { live lesson } \\
\text { Give feedback to teachers on } \\
\text { students' understanding and } \\
\text { ideas }\end{array}$ & LMS or SRS & \multirow{5}{*}{$\begin{array}{l}\text { Use LMS features } \\
\text { and instant } \\
\text { messaging } \\
\text { platforms to stay } \\
\text { in communication } \\
\text { throughout the } \\
\text { sequence. }\end{array}$} \\
\hline Synchronous & $\begin{array}{l}\text { 2. Live lesson through } \\
\text { VCS } \\
\text { a. Warm-up activity } \\
\text { while students log } \\
\text { in } \\
\text { b. Teaching + activity } \\
\text { c. Set post-live lesson } \\
\text { task (in detail) } \\
\text { d. Stay 'on' for } \\
\text { students who have } \\
\text { questions }\end{array}$ & $\begin{array}{l}\text { Provide regularity } \\
\text { Answer questions } \\
\text { Interaction between learner- } \\
\text { learner / teacher-learner }\end{array}$ & $\begin{array}{l}\text { VCS (e.g. } \\
\text { Zoom) } \\
\text { combined with } \\
\text { SRS, Game- } \\
\text { based } \\
\text { platforms, and } \\
\text { presentation } \\
\text { software }\end{array}$ & \\
\hline \multirow[t]{2}{*}{ Asynchronous } & 3. Post-live lesson task & $\begin{array}{l}\text { Check student understanding } \\
\text { / provide practice in subject } \\
\text { area } \\
\text { Consolidate and continue } \\
\text { learning }\end{array}$ & LMS & \\
\hline & $\begin{array}{l}\text { 4. Analyse students' } \\
\text { responses }\end{array}$ & $\begin{array}{l}\text { Analyse student } \\
\text { understanding, development } \\
\text { and areas for improvement }\end{array}$ & $\begin{array}{l}\text { Analytics on } \\
\text { various } \\
\text { platforms e.g. } \\
\text { LMS }\end{array}$ & \\
\hline $\begin{array}{l}\text { Asynchronous } \\
\text { and/or } \\
\text { synchronous }\end{array}$ & $\begin{array}{l}\text { 5. Individual / class } \\
\text { feedback }\end{array}$ & $\begin{array}{l}\text { Provide feedback to learner } \\
\text { on understanding, } \\
\text { development and areas for } \\
\text { improvement }\end{array}$ & $\begin{array}{l}\text { Annotation } \\
\text { Software / } \\
\text { Video with } \\
\text { answers / } \\
\text { Optional } \\
\text { synchronous } \\
\text { tutorials / } \\
\text { upload } \\
\text { feedback to } \\
\text { LMS }\end{array}$ & \\
\hline
\end{tabular}

Fig. 3 Blended online instructional sequence

to help learners prepare for the live lesson and provide feedback to the teacher on students' understanding and ideas. Literature suggests that short tailor-made videos by the teacher are preferable to ready-made videos (Bond, 2020). These should be followed by personalised questions or short activities. In addition, the LMS should be updated regularly and should periodically remind students to check if activities and materials have been uploaded (Kim, 2017).

In the second stage, the teacher and students participate in a synchronous live lesson through a VCS. Teachers can integrate other platforms and tools, such as SRS and collaborative tools to provide multiple modes of interaction. It is important that instructions and activities are clear and concise, and questions posed are appropriate and meaningful to minimise student disengagement (Gomes \& Linton, 2011). In addition, to effectively conduct synchronous online lessons, it is important for teachers to have the relevant competencies to facilitate interaction during lessons (Cong, 2020; Moorhouse et al., 2021; Rehn et al., 2016). 
In the third stage, the teacher assigns a post-live lesson activity leveraging the LMS or other digital technologies. The post-live lesson activity should extend the students' learning forward while providing feedback to teachers on students' performance and needs, similar to the role of homework in the in-person classroom (Magalhães et al., 2020).

The fourth and fifth stage involve the teacher analysing and providing feedback in the post-live lesson activity. In these final stages, teachers need relevant digital feedback literacies to select the appropriate mode and format, and to provide the feedback to learners effectively (Gravett, 2020). Teachers need to keep in communication with students during the sequence to ensure they keep up with their learning and actively participate in learning. This can be done through the LMS (Kim, 2017) and instant messaging platforms.

The stages provided opportunities for students to work independently and collaboratively in asynchronous learning environments, and opportunities for teachers to provide live input, respond to questions and communicate in real time during synchronous lessons. The pre- and post- lesson tasks allow teachers to check for understanding formatively and allow learners to respond through their preferred mode according to task and learner variables (Moorhouse \& Beaumont, 2020b).

While models such as the 'The dimensions of blended learning model' (iNACOL, 2011) provide a way for us to conceptualise blended learning, it is important that teachers also have a model they can apply to their teaching (Cleveland-Innes \& Garrison, 2012; Morgan, 2020; Wang, 2021). The 'Blended Online Instructional Sequence' Model provides a possible learning sequence for teachers to do this, therefore, helping address the current lack of instructional models and suggestions of best practice in virtual schools and online primary and secondary school teaching (Dipietro, 2010; Toppin \& Toppin, 2015). It is important to add that even with the model presented in Fig. 3, teachers need the relevant skills and competencies to teach effectively online (Cleveland-Innes \& Garrison, 2012; Pulham \& Graham, 2018), as even the selection of LMS can have an impact on teaching and learning (Kim, 2017). It is, therefore, important that as part of pre-service and in-service teacher training, as well as the development of teachers' technological competencies (Sánchez-Cruzado et al., 2021; Taghizadeh \& Yourdshahi, 2019), they are also provided with possible instructional models, such as Fig. 3, that can be used to design and implement a sequence of learning online. This will aid their decision-making, planning, delivery, assessment, and hopefully, student learning experiences.

\section{Limitations and suggestions for further research}

The current study demonstrates how teachers responded to the suspension of inperson classes and shifted their teaching online with digital technology to keep teaching despite the pandemic (Dhawan, 2020). They used a variety of digital technologies and approaches to aid their students' learning. The data analysis suggests that neither synchronous nor asynchronous-only approaches are sufficient to support student learning; instead a blended approach is required. Though the reasons for teachers needing to teach online are not ideal, or ever desired, this 
period has provided us with an opportunity to explore and consider how teachers can employ technology to aid learning at a distance.

There were some limitations in the study. Firstly, the sample size was small. Secondly, the sampling method, while being selected due to the time sensitive nature of the situation, may mean it does not represent the whole population. Thirdly, the findings reflect teachers' practices at a specific moment in time; March 2020 (survey) and April 2020 (interview). These may have changed as the situation regarding the class suspension developed. Furthermore, the findings are context specific, representing the situation in Hong Kong. COVID-19 has impacted different countries and contexts very differently. Hong Kong, while closing schools earlier than most, has had fewer per capita cases than other contexts (Goodwin, 2020). Fourthly, the data was self-reported. Readers should take these limitations into consideration when discerning the findings relevant to their contexts.

In addition, the 'Blended Online Instructional Sequence' Model presented in Fig. 3, while emerging from the findings and related to literature, has not been tested. We encourage other scholars and teachers to test the model and adapt it based on the needs of their specific contexts. Furthermore, we encourage scholars to examine other instructional modes that could be used to facilitate primary and secondary online learning, similar to Horvitz and colleagues' (2019) study of community colleges. The situation caused by COVID-19 is unprecedented in modern times. While we all wish to see a quick return to normalcy, the context we are living through has broadened the scope for research. Clearly, explorations of teachers' practices in different contexts are warranted, as is the perspective of other relevant stakeholders, such as students and parents. Furthermore, as schools begin to reopen, it will be worthwhile exploring the role technology plays in helping learners and teachers transition back to in-person teaching while maintaining social distancing and other preventative measures. The post-COVID-19 classroom, while requiring additional digital competencies (Sánchez-Cruzado et al., 2021), will also require instructional models to aid teachers' decision-making, planning and instruction.

Supplementary Information The online version contains supplementary material available at https:// doi.org/10.1007/s40692-021-00195-8.

\section{References}

Allen, I. E., Seaman, J., Poulin, R., \& Straut, T. T. (2016). Online report card. Tracking online education in the United States. Babson Survey Research Group and Quahog Research Group.

Barbour, M. K., \& Reeves, T. C. (2009). The reality of virtual schools: A review of the literature. Computers \& Education, 52(2), 402-416. https://doi.org/10.1016/j.compedu.2008.09.009

Bjørgen, A. M., Fritze, Y., \& Haugsbakk, G. (2021). Dealing with increased complexity. Teachers' reflections on the use of tablets in school. Pedagogies: An International Journal, 1-16. https://doi.org/10. 1080/1554480x.2021.1897010.

Bond, M. (2020). Facilitating student engagement through the flipped learning approach in K-12: A systematic review. Computers \& Education, 151, 103819. https://doi.org/10.1016/j.compedu.2020. 103819

Bozkurt, A., Jung, I., Xiao, J., Vladimirschi, V., Schuwer, R., Egorov, G., \& Rodes, V. (2020). A global outlook to the interruption of education due to COVID-19 Pandemic: Navigating in a time of uncertainty and crisis. Asian Journal of Distance Education, 15(1), 1-126. https://doi.org/10.5281/ zenodo. 3878572 
Braun, V., \& Clarke, V. (2006). Using thematic analysis in psychology. Qualitative Research in Psychology, 3(2), 77-101. https://doi.org/10.1191/1478088706qp063oa

Braun, V., Clarke, V., Boulton, E., Davey, L., \& McEvoy, C. (2020). The online survey as a qualitative research tool. International Journal of Social Research Methodology. https://doi.org/10.1080/ 13645579.2020.1805550

Carrier, M., \& Nye, A. (2017). Empowering teachers for the digital future. In M. Carrier, R. M. Damerow \& K. M. Bailey (Eds.), Digital language learning and teaching: Research, theory, and practice (pp. 208-221). Routledge.

Chai, C. S., \& Kong, S. C. (2016). Professional learning for 21st century education. Journal of Computers in Education, 4(1), 1-4. https://doi.org/10.1007/s40692-016-0069-y

Cheung, A. (2021). Language teaching during a pandemic: A case study of zoom use by a secondary ESL teacher in Hong Kong. RELC Journal. https://doi.org/10.1177/0033688220981784.

Clark, T. \& Z. Berge. (2005). Virtual schools and eLearning: Planning for success. Paper presented at the Annual Conference on Distance Teaching and Learning, The Board of Regents of the University of Wisconsin System.

Cleveland-Innes, M., \& Garrison, D. R. (2012). Higher education and postindustrial society: New ideas about teaching, learning, and technology. In The next generation of distance education (pp. 221233). Springer, Boston, MA.

Cohen, L., Manion, L., \& Morrison, K. (2011). Research methods in education (7th ed.). Routledge.

Cong, L. M. (2020). Successful factors for adoption of synchronous tools in online teaching at scale. In T. McLaughlin, A. Chester, B. Kennedy, \& S. Young (Eds.), Tertiary education in a time of change (pp. 39-60). Springer. https://doi.org/10.1007/978-981-15-5883-2_4.

Cuban, L. (2001). Oversold and underused. Harvard University Press.

Dhawan, S. (2020). Online learning: A Panacea in the time of COVID-19 crisis. Journal of Educational Technology Systems, 49(1), 5-22. https://doi.org/10.1177/0047239520934018

Dipietro, M. (2010). Virtual school pedagogy: The instructional practices of K-12 virtual school teachers. Journal of Educational Computing Research, 42(3), 327-354. https://doi.org/10.2190/ec.42.3.e

González-Lloret, M. (2020). Collaborative tasks for online language teaching. Foreign Language Annals, 53(2), 260-269. https://doi.org/10.1111/flan.12466

Goodwin, P. M. (2020). Distancing, testing \& isolation stalled Hong Kong COVID-19 outbreak. Oncology times, 42(12), 25-30. https://doi.org/10.1097/01.COT.0000681576.38684.73

Gravett, K. (2020). Feedback literacies as sociomaterial practice. Critical Studies in Education. https:// doi.org/10.1080/17508487.2020.1747099

Hesse-Biber, S. (2010). Qualitative approaches to mixed methods practice. Qualitative Inquiry, 16(6), 455-468. https://doi.org/10.1177/1077800410364611

Hockly, N., \& Dudeney, G. (2018). Current and future digital trends in ELT. RELC Journal, 49(2), 164-178.

Hodges, C., Moore, S., Lockee, B., Trust, T., \& Bond, A. (2020). The difference between emergency remote teaching and online learning. Educause Review Online. Retrieved from https://er.educause. edu/articles/2020/3/the-difference-between-emergency-remote-teaching-and-online-learning

Holden, R. R. (2010). Face validity. Corsini Encyclopedia of Psychology. https://doi.org/10.1002/97804 70479216.corpsy0341

Horvitz, B. S., Garcia, L. R., Mitchell, R. G., \& Calhoun, C. D. (2019). An examination of instructional approaches in online technical education in community colleges. Online Learning. https://doi.org/ 10.24059/olj.v23i4.1613.

International Association for K-12 Online Learning. (2011). National standards for quality online teaching (Version 2). Vienna, VA: Author. Retrieved from https://www.inacol.org/resource/inacol-natio nal-standards-for-quality-online-teaching-v2

Kim, D. (2017). The impact of learning management systems on academic performance: Virtual Competency and student Involvement. Journal of Higher Education Theory and Practice, 17(2), 23-35.

Kong, S. C., Looi, C. K., Chan, T. W., \& Huang, R. (2017). Teacher development in Singapore, Hong Kong, Taiwan, and Beijing for e-learning in school education. Journal of Computers in Education, 4(1), 5-25.

Magalhães, P., Ferreira, D., Cunha, J., \& Rosário, P. (2020). Online vs traditional homework: A systematic review on the benefits to students' performance. Computers \& Education, 152, 103869. https:// doi.org/10.1016/j.compedu.2020.103869 
Moller, L., Robison, D., \& Huett, J. B. (2012). Unconstrained learning: Principles for the next generation of distance education. In The next generation of distance education (pp. 1-19). Boston, MA: Springer.

Moorhouse, B. L., \& Beaumont, A. M. (2020a). Utilizing video conferencing software to teach young language learners in Hong Kong during the COVID-19 class suspensions. TESOL Journal, 11(3). https://doi.org/10.1002/tesj.545.

Moorhouse, B. L., \& Beaumont, A. M. (2020b). Involving Parents in Their Children's School-Based English Language Writing Using Digital Learning. RELC Journal, 51(2), 259-267. https://doi.org/10. $1177 / 0033688219859937$.

Moorhouse, B. L., \& Kohnke, L. (2021). Thriving or surviving emergency remote teaching necessitated by COVID-19: University teachers' perspectives. The Asia-Pacific Education Researcher, 30(3), 279-287. https://doi.org/10.1007/s40299-021-00567-9.

Moorhouse, B. L., Li, Y., \& Walsh, S. (2021). E-Classroom Interactional Competencies: Mediating And Assisting Language Learning During Synchronous Online Lessons. RELC Journal, 003368822098527. https://doi.org/10.1177/0033688220985274.

Morgan, H. (2020). Best practices for implementing remote learning during a pandemic. The Clearing House, 93(3), 135-141. https://doi.org/10.1080/00098655.2020.1751480

Morse, J. M. (2010). Simultaneous and sequential qualitative mixed method designs. Qualitative Inquiry, 16(6), 483-491. https://doi.org/10.1177/1077800410364741

Nunan, D., \& Bailey, K. M. (2009). Exploring second language classroom research: A comprehensive guide. Heinle, Cengage Learning.

Peachey, N. (2017). Synchronous online teaching. In M. Eds Carrier, R. M. Damerow, \& K. M. Bailey (Eds.), Digital language learning and teaching. New York: Routledge.

Pulham, E., \& Graham, C. R. (2018). Comparing K-12 online and blended teaching competencies: A literature review. Distance Education, 39(3), 411-432. https://doi.org/10.1080/01587919.2018.14768 40

Rehn, N., Maor, D., \& McConney, A. (2016). Investigating teacher presence in courses using synchronous videoconferencing. Distance Education, 37(3), 302-316. https://doi.org/10.1080/01587919. 2016.1232157

Rehn, N., Maor, D., \& McConney, A. (2018). The specific skills required of teachers who deliver K-12 distance education courses by synchronous videoconference: Implications for training and professional development. Technology, Pedagogy and Education, 27(4), 417-429. https://doi.org/10.1080/ 1475939x.2018.1483265

Rozitis, C. P. (2017). Instructional design competencies for online high school teachers modifying their own courses. TechTrends, 61(5), 428-437. https://doi.org/10.1007/s11528-017-0204-2

Sánchez-Cruzado, C., Santiago Campión, R., \& Sánchez-Compaña, M. T. (2021). Teacher digital literacy: The indisputable challenge after COVID-19. Sustainability, 13(4), 1858. https://doi.org/10. 3390/su13041858

Schuetz, R. L., Biancarosa, G., \& Goode, J. (2018). Is technology the answer? Investigating students' engagement in math. Journal of Research on Technology in Education, 50(4), 318-332. https://doi. org/10.1080/15391523.2018.1490937

Serwatka, J. (2002). Improving student performance in distance learning courses. The Journal of Technological Horizons in Education, 29(9), 46-52.

Shah, M. (2014). Impact of management information systems (MIS) on school administration: What the literature says. Procedia - Social and Behavioral Sciences, 116, 2799-2804. https://doi.org/10. 1016/j.sbspro.2014.01.659

Taghizadeh, M., \& Yourdshahi, Z. H. (2019). Integrating technology into the young learners' classes: Language teachers' perceptions. Computer Assisted Language Learning, 33(8), 982-1006. https:// doi.org/10.1080/09588221.2019.1618876

Tay, L. Y., Melwani, M., Ong, J. L., \& Ng, K. R. (2017). A case study of designing technology-enhanced learning in an elementary school in Singapore. Learning: Research and Practice, 3(2), 98-113. https://doi.org/10.1080/23735082.2017.1350737

Toppin, I. N., \& Toppin, S. M. (2015). Virtual schools: The changing landscape of K-12 education in the U.S. Education and Information Technologies, 21(6), 1571-1581. https://doi.org/10.1007/ s10639-015-9402-8

Voogt, J., Knezek, G., Christensen, R., \& Lai, K. W. (Eds.). (2018). Second handbook of information technology in primary and secondary education. New York: Springer. 
Wang, C. X. (2021). CAFE: An instructional design model to assist K-12 teachers to teach remotely during and beyond the COVID-19 pandemic. TechTrends, 65, 8-16. https://doi.org/10.1007/ s11528-020-00555-8

White, C. (2003). Language learning in distance education. Cambridge University Press.

Publisher's Note Springer Nature remains neutral with regard to jurisdictional claims in published maps and institutional affiliations.

Benjamin Luke Moorhouse Ed.D., is an assistant professor in the Department of Education Studies, Hong Kong Baptist University, Hong Kong, PRC. His research focuses on initial teacher education, teaching young English language learners, and the role of technology in English language teaching and learning.

Kevin M. Wong Ph.D., is an Assistant Professor in the Graduate School of Education and Psychology at Pepperdine University in Los Angeles, California, USA. His research focuses on multilingual education, early word learning, and the affordances of technology in teaching and learning. 